PostGRAD. MED. J. (1965), 41, 10

\title{
IMMUNIZATION AGAINST TETANUS
}

\author{
M. W. L. GeAR, M.A., B.M., B.Ch., F.R.C.S. \\ Surgical Registrar, \\ (Formerly Senior Casualty Officer), King's College Hospital, S.E.5.
}

IN A RECENT preliminary communication (Smith, Evans, Jones, Gear, Cunliffe and Barr, 1963) the results of a clinical trial of adsorbed tetanus toxoid were presented. This demonstrated the efficacy and safety of simultaneous injections of adsorbed toxoid and tetanus antitoxin. Casualty officers and general practitioners are frequently faced with the problem of immunization against tetanus and are hampered by doubts about the use of antitoxin, the practicability of active immunization and the selection of cases. It is hoped in this article to solve some of these problems and to provide a scheme which may be used routinely.

\section{The Problem}

It has been estimated (Gissane, 1962) that one in ten of the population is injured annually; the numbers would undoubtedly be even higher if all trivial injuries were included. Any break in the skin following injury may be contaminated with tetanus organisms. For example, in 1961 a girl of 14 years contracted tetanus following a superficial abrasion of her eyebrow sustained at school during a game of netball. The disease presented in a subacute form, the girl having received prophylactic antitetanus serum in the Casualty Department; treatment for tetanus was begun early and the patient recovered. This is a good illustration of infection following the most trivial scratch, and of the importance of adequate prophylaxis against tetanus in every injury involving a break in the skin.

Farm and sewer workers, sportsmen, children, and those injured in road accidents run the greatest risk. Tetanus accounts for about 25 deaths annually (Registrar General, 1961). It is always a serious disease, carrying a mortality in this country of over $20 \%$ (Conybeare, 1959) and mortality rates up to $60 \%$ are found in other parts of the world which have less comprehensive medical services (Johnstone, 1958; Brown, Mohamed, Montgomery, Armitage and Laurence, 1960). The main methods of tetanus prophylaxis currently used are:-

Passive immunization, using 1500 units antitoxin in antitetanus serum.
Active immunization, using plain formol toxoid. Three injections of $0.5 \mathrm{ml}$. are given, the first two separated by six weeks and the third given six to twelve months later.

Obviously active immunization of the entire population is desirable, as this is known to provide effective protection and to have few risks, as Army experience during the Second World War showed.

The problem facing the doctor is one of protecting a large number of injured patients with varying degrees of immunity. Some of the patients may also have been sensitized to horse serum.

Parish and Cannon (1962) suggest the following scheme for protection following injury:- Immune patients receive a booster dose of $0.5 \mathrm{ml}$. of toxoid. Patients with doubtfus histories of immunization are presumed to be non-immune, and therefore receive antitoxifo followed six weeks later by the first of the usual course of three toxoid injections.

There are several difficulties associated with this scheme. First, the passive immunity conferred by tetanus antitoxin is short livedusually lasting only about two weeks. (Barr and Sachs, 1955). It may be even less in patients who previously have had horse serum. Second, a detectable level of antitoxin is not usually produced in primary active immunization until five to fourteen days after the second dose of toxoid, i.e. about 12-13 weeks after injury. Thus there is a period of about ten weeks after the antitoxin has been eliminated, during which the patient is unprotected. Third, six weeks elapse before the start of active immunization and for a variety of reasons many patients do not return. A subsequent injection of antitoxin which would be necessary if such patients were treated again later may not only produce allergic reactions but also may fail to protect because of its rapid elimination. (Payling Wright, 1958; Godfrey, Parsons, Rawstron, 1960).

Widely differing schemes of immunization are in use in different hospitals. While some follow the recommendations of Parish and Cannon, and provide facilities for full immuni- 
TABLE 1

TETANUS ANTITOXIN IN THE SERA OF 64 PATIENTS WHEN ACTIVE IMMUNIZATION WITH PLAIN TOXOID PREOEDED PASSIVE IMMUNIZATION BY 18-24 HOURS

\begin{tabular}{lllllllllll} 
& \multicolumn{8}{c}{ Antitoxin Titres - Units $/ \mathrm{ml}$ serum } \\
& 0.02 & $0.02-$ & $0.05-$ & $0.1-$ & $0.2-$ & $0.5-$ & $1-$ & $2-$ & $5-$ & $10-20+$ \\
No. of Patients & 10 & - & 2 & 3 & 7 & 2 & 6 & 10 & 6 & 18 \\
Percentage & 15.6 & - & 3.1 & 4.6 & 10.9 & 3.1 & 9.3 & 15.6 & 9.3 & 28.1
\end{tabular}

zation, some direct the patient to his own doctor or to a local authority clinic, others do not attempt active immunization at all. There is a great need for a simple recognised procedure which can be adopted by general practitioners and hospital casualty departments.

Combined active and passive immunization would circumvent many of the difficulties discussed above. This has been successfully practised in diptheria prophylaxis (Fulton, Wells, Taylor and Wilson, 1941), but Barr and Sachs (1955) found that active immunity to tetanus was markedly depressed if antitetanus serum was given at the same time as plain toxoid.

Trials were undertaken at King's College Hospital of procedures to provide passive immunity without interference with the active immunity. The first trial was based on the hypothesis that if plain toxoid preceded antitetanus serum by as little as one day, interference might not occur. This was unsuccessful, but the results are presented for comparison with those of the second trial, which was made with adsorbed toxoid, a more potent prophylactic.

Experience in other countries has shown that if adsorbed toxoid is used there is no interference with the production of active immunity (Gold and Bachers, 1943, Ericsson, 1948, Tasman and Huygen, 1962). Adsorbed toxoid was previously unobtainable in this country, but in May, 1962 adsorbed toxoid (Burroughs Wellcome) became available for clinical trial.

\section{The First Trial}

In this trial the first injection of plain toxoid was given on the day of injury and was followed the next day by an injection of antitoxin in a different site. Second and third toxoid injections were given at six weeks and six months from the time of the injury.

Samples of serum were obtained two weeks after the second dose of toxoid, i.e. 8 weeks after injury. At this time if toxoid alone had been used all the patients would be expected to have developed a protective level of antitoxin. It is clear from Table 1 that an adequate level of antitoxin was not produced in $15.6 \%$ of patients and that in these patients the antitoxin had reduced active immunity. At least 0.02 units antitoxin $/ \mathrm{ml}$. of serum is generally considered to give adequate protection. (Tasman and Huygen, 1962).

It is also clear that some of the high titres obtained were due to some patients having had previous toxoid injections. In subsequent triáls such patients with pre-existing basal immunity were identified by estimating the serum antitoxin titres before the second toxoid injection. A detectable level of antitoxin at this time was taken to indicate that the patient had previously received an injection of toxoid.

\section{The Second Trial}

Trials with adsorbed toxoid were started simultaneously at King's College Hospital and University College Hospital in May, 1962. Injured persons requiring prophylaxis with antitetanus serum were offered also immunization with adsorbed tetanus toxoid; they were given 1,500 units of antitetanus serum intramuscularly into one arm and immediately afterwards $0.5 \mathrm{ml}$. of adsorbed toxoid intramuscularly into the other. Second and third doses of toxoid were given respectively six weeks and six months later. For the purposes of the trial, two blood samples were taken, one at the time of the second toxoid injection and another two weeks later, from patients who considered that they had not received previous active immunization against tetanus. A preliminary communication of this trial has already been made (Smith and others, 1963). At King's College Hospital 76 patients took part in the trial and on the basis of the titres obtained with the serum samples taken at the time of the second dose, 55 patients (Group A) were considered non-immune, having a level of less than $0.02 \mathrm{u} / \mathrm{ml}$. and the remaining 21 (Group B) were found to be immune with titres of more than $0.02 \mathrm{u} / \mathrm{ml}$.

Table 2 shows the response of all the 76 patients to simultaneous active and passive 
TABLE 2

TETANUS ANTITOXIN IN THE SERA OF 76 PATIENTS WHEN ACTIVE IMMUNIZATION WITH ADSORBED TOXOID WAS GIVEN AT THE SAME TIME AS PASSIVE IMMUNIZATION

\begin{tabular}{|c|c|c|c|c|c|c|c|c|c|c|c|}
\hline & & & Antit & $\operatorname{xin} T 1$ & res- & Inits / & nl. se & um & & & \\
\hline & Total & 0.02 & $0.02-$ & $0.05-$ & $0.1-$ & 0.2 & $0.5-$ & $1-$ & $2-$ & $5-$ & $10-20+$ \\
\hline $\begin{array}{l}\text { ne } \\
\text { Immunized }\end{array}$ & $\begin{array}{l}55 \\
21\end{array}$ & 二 & 1 & 1 & 1 & $\underline{3}$ & $\begin{array}{l}8 \\
2\end{array}$ & 12 & $\begin{array}{r}14 \\
6\end{array}$ & $\begin{array}{r}11 \\
4\end{array}$ & $\begin{array}{l}4 \\
9\end{array}$ \\
\hline & 76 & - & 1 & 1 & 1 & 3 & 10 & 12 & 20 & 15 & 13 \\
\hline
\end{tabular}

immunization. Antitoxin titres of over 0.02 units $/ \mathrm{ml}$. were given by all in response to the 2 doses of toxoid. The results obtained from those with pre-existing immunity (Group B) have been included because they illustrate well the higher antitoxin levels attained when toxoid is given as a "booster" dose. Antitoxin levels over 2 units $/ \mathrm{ml}$. were found in $19(90 \%)$ of these 21 , as compared with only $29(53 \%)$ of the 55 non-immune subjects.

\section{Reactions}

The frequency of reactions to antitoxin and toxoid during the trial of adsorbed toxoid were determined by examining the record cards of one thousand consecutive patients. These cards were also used to assess the number of patients who returned to complete the course of toxoid injections; $380(38 \%)$ did so. This figure may be unduly low, as some patients chose to complete the course at a local hospital or under their general practitioner.

\section{Reactions to Antitetanus Serum}

A test dose of $0.1 \mathrm{ml}$. of serum (150 units) was always given subcutaneously before the full dose of 1500 units. 89 patients $(8.9 \%)$ had some degree of local reaction to the test dose. About half of these subsequently received the full dose safely with an antihistamine (chlorpheniramine maleate $10 \mathrm{mg}$. i.m.) given to safeguard against further reactions. The remainder did not receive any further dose of serum as the casualty officer judged the risk to be too great in view of a firm history of a previous allergy, a generalised reaction or a large local reaction to the test dose. In such cases a prophylactic course of penicillin was given in a dose of a million units daily for five days.

One patient developed urticaria, asthma and hypotension shortly after the $0.1 \mathrm{ml}$. test dose, a reaction which necessitated admission to hospital and treatment with adrenaline and antihistamines. This patient's history did not suggest an allergic tendency and thus a diluted test dose was not used.
No patient in the trial incurred an immediate. serious reaction to the full dose, but one patien? came to casualty during the trial with a severe generalised reaction following a full dose of antiserum given by his general practitioneo without the precaution of a test dose. He hap a history of previous serum sickness followings antiserum and required treatment in hospital with hydrocortisone as well as antihistamines:

Delayed reactions, seven to fourteen days after injection of the full dose, were usuallys localised to the site of injection where swelling. or erythema occurred; sometimes a generalised urticaria resulted. Delayed reactions were experienced by 41 patients $(4.1 \%)$.

In all, 132 patients $(13.2 \%)$ had some degree of reaction to antitoxin. This figure might wello have been higher if those patients who attende $d^{\text {r }}$ other hospitals or their general practitione for treatment of a delayed reaction could have been included. The use of a test dose limits the incidence of severe reactions but these mayo be fatal; several deaths a year are probablyo attributable to serum. (Conybeare, 1959). Of course if active immunization could be instituted in everyone from childhood, the use of anti serum could be greatly diminished.

\section{Reactions to Adsorbed Toxoid}

Only nine patients $(0.9 \%)$ complained of reactions to adsorbed toxoid. In eight patient the reaction consisted of slight induration ancs pain at the site of injection which subsided rapidly without treatment. One patient had a pronounced local reaction consisting of urtio carial swelling of the skin of the upper arm? and shoulder which faded over a few days during treatment with an antihistamine. Hew had not received tetanus toxoid before and immunization was completed without trouble $e^{\omega}$ using fluid toxoid. No systemic reactions occurred.

\section{Conclusions}

The results of this trial indicate that adsorbed toxoid may be given simultaneously with $150 \%$ units of antitoxin and that after the second 
dose of toxoid, six weeks later a protective level of antitoxin results. The advantages of this procedure are:-

(a) Active immunity produces a protective level of antitoxin eight weeks after injury. Thus the time during which the patient is unprotected after passive immunization is reduced to less than six weeks.

(b) Patients who do not return for their second dose of toxoid have had their antibody producing mechanism 'sensitized' so that a dose of toxoid given at a later date may yet result in the production of a protective level of antitoxin. Immunity however cannot be presumed until they have received a complete course of toxoid.

\section{Proposed Immunization Scheme}

It is considered advisable to give tetanus prophylaxis to all patients who have had any break in the skin. It is not possible to be certain that any wound, however slight, may not be infected with tetanus organisms. At King's College Hospital, it has been decided that at present there is insufficient evidence to allow tetanus antitoxin to be discarded as an immediate protective measure.

1. Immune Patients: (Those within twelve months of receiving two correctly spaced doses of tetanus toxoid; or those within five years of the third or of a subsequent booster dose).

These patients should receive a booster dose of $0.5 \mathrm{ml}$. of toxoid, either fluid or adsorbed type, and antitoxin is not given.

2. Non-immune Patients: (All others).

(a) On the day of injury antitoxin is given in a dose of 1500 units $(1 \mathrm{ml}$.). In all cases a test dose of $0.1 \mathrm{ml}$. should be injected subcutaneously, and the patient examined in half an hour, before a further $0.9 \mathrm{ml}$. is given. In those with a history of severe allergic manifestations, diluted test doses should be used.

(b) Adsorbed toxoid (in a dose of $0.5 \mathrm{ml}$.) is given intramuscularly into the other arm at the same time as the antitoxin. A second dose of adsorbed toxoid is given six weeks later and a third six to twelve months after that. The third injection may be of either plain or adsorbed toxoid.

\section{Allergic Patient;}

If it is not possible to give antitetanus serum because of previous or present severe allergic manifestations, penicillin should be given, intramuscularly, in doses of a million units daily for five days and the patient immunized actively, with adsorbed toxoid (Lowbury, Batten and London, 1961).

All wounds must receive adequate surgical $\stackrel{\mathbb{\infty}}{\circ}$ cleaning, debridement and dressing. All $c$. patients who are immunized are given a card on which is noted the injections they have received and instructions are given for their return to complete their active immunization. At King's College Hospital a weekly tetanus immunization clinic is held for this purpose in the casualty department, and it has been found that two nurses can deal with attendances in two hours.

\section{Summary}

The problem of immunization against tetanus is discussed and methods currently used are described.

The results of two clinical trials of simultaneous active and passive immunization are presented. It was clearly demonstrated that adsorbed toxoid may be given simultaneously with 1500 units of antitoxin, and that after the second dose of toxoid six weeks later a protective level of antitoxin resulted in 100\% of 55 patients who had no previous immunity to tetanus.

Reactions to tetanus antitoxin and to ado sorbed toxoid in a series of 1,000 patients are discussed.

An immunization scheme is suggested that is suitable for routine use in all casualty departments and general practitioner surgeries.

I wish to thank Mr. L. T. Cotton and Professor A. C. Cunliffe for their generous assistance and helpful advice and criticism; Miss Mollie Barr for performing serum antitoxin estimations; and the staff of the casualty department of King's College Hospital for their co-operation.

I would like to acknowledge the work of $\mathrm{Dr}$ J. Myles in the first trial.

I would also like to acknowledge the secretarial work of Miss C. Childs and Mrs. V. Barrett.

\section{REFERENCES}

BARR, M., and SACHS, A. (1955): Army Pathology Advisory Committee Report on the Investigation into the Prevention of Tetanus in the British Army.

Brown, A., Mohamed, S. D., Montgomery, R. D., Armitage, P., and Laurence, D. R. (1960): Value of a Large Dose of Antitoxin in Clinical Tetanus, Lancet, ii, 227.

Conybeare, E. T. (1959): Tetanus in the Civilian Population of England and Wales, Proc. roy. Soc. Med., 52, 112.

ERICSSON, H. (1948): Studies on Tetanus Prophylaxis. J. clin. Path., 1, 306.

Fulton, F., Wells, A. Q., TAYlor, J., and Wilson, G. S. (1941): Combined Active and Passive Immunisation against Diphtheria, Brit. med. J., ii, 759. 
Godfrey, M. P., Parsons, V., and Rawstron, J. R. (1960): Rapid Destruction of Anti-tetanus Serum in a Patient previously Sensitized to Horse Serum, Lancet, ii, 1229.

GolD, M., and BACHERS, M. (1943): Combined Active Passive Immunization against Tetanus, J. Immunology, 47, 335.

GissaNe, W. (1962): The Basic Surgery of Major Road Injuries, Ann. roy. Coll. Surg. Eng., 30, 281. JohnSTONE, D. D. (1958): Tetanus in Nigeria. Review of 100 cases treated in Ibadan, Proc. roy. Soc. Med., 51, 997.

Lowbury, E. J. L. BATten, R. L., and London, P. S. (1961): Antitetanus Immunization, Brit. med. J., ii, 1782 .
Parish, H. J., and Cannon, D. A. (1962): Antisera, Toxoids, Vaccines and Tuberculins in Prophylaxis and Treatment, Edinburgh and London: E. \& S. Livingstone.

Registrar General (1963): Statistical Review of England and Wales for the year 1961. Part I: Tables, Medical. London: H.M.S.O.

Smith, J. W. G., Evans, D. G., Jones, D. A., Gear, M. W. L., CUNLIFFE, A. C., and BARR, M. (1963): Simultaneous Active and Passive Immunization against Tetanus, Brit. med. J., i, 237,.

Tasman, A., and Huygen, F. J. A. (1962): Immunization against Tetanus of Patients given Injections of Antitetanus Serum, Bull. Wld. Hlth. Org., 26, 397. 